
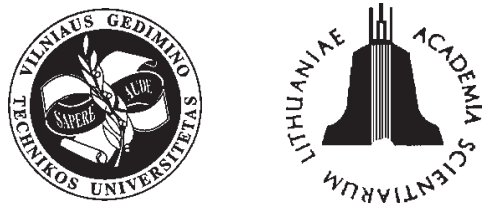

ISSN 1392-3730

JOURNAL OF CIVIL ENGINEERING AND MANAGEMENT

http:/www.jcem.vgtu.lt

2005, Vol XI, No 1, 65-71

\title{
OPTIMUM REINFORCEMENT DESIGN OF CONCRETE CROSS-SECTIONS CONSIDERING DEFORMATION CONSTRAINTS
}

\author{
Erich Raue, Stephan Hahn \\ Dept of Reinforced Concrete Structures, Bauhaus-University Weimar, Marienstrasse 13, D-99421 Weimar, \\ Germany.E-mail: erich.raue@bauing.uni-weimar.de, stephan.hahn@bauing.uni-weimar.de
}

Received 23 Dec 2004; accepted 11 Feb 2005

\begin{abstract}
The paper concerns the optimum reinforcement design for $\mathrm{r} / \mathrm{c}$ cross-sections through the simultaneous consideration of multiple load cases. The problem is solved by methods of non-linear mathematical programming. In the first part, the calculation model for cross-sections is derived from extremum principles. The second part deals with the comparison of design strategies using step-by-step and parallel calculation. Finally, a numerical example is provided. The discussion shows the efficiency of the presented algorithm compared with traditional design concepts. The strategy demonstrates a considerable decrease in the amount of reinforcement required.
\end{abstract}

Keywords: optimum design, cross-section, reinforced concrete, multiple loading, mathematical programming.

\section{Introduction}

A huge amount of computation algorithms exists for the calculation of reinforced concrete cross-sections. Thus the minimum cost design is a special subject. The costs are generally divided into those for steel, concrete and formwork. These models are provided with objectives such as topology, shape or cost functions. Models that use these methods can be found in [1-3]. However, these models consider only one load case as an external action simultaneously. The effect of multiple loading is neglected.

The design of cross-sections under different load cases is one of the standard tasks in construction. Traditionally, load cases will be treated separately and the resulting maximum reinforcement will be used. If the envelope reinforcement is chosen, an ineffective utilisation of reinforcement may result.

However, there are few optimum design models that can describe reinforced concrete sections at ultimate limit state. Here the influences of cracking and non-linear stress distribution must also be considered. As mentioned before, a major disadvantage of these models is the single load case consideration in section design.

In this article, a numerical approach is used for determining the reinforcement by taking multiple load cases into account.

\section{Mechanical models}

In this chapter, the derivation of optimisation problems from variational principles is shown. Therefore, the models from $[4,5]$ are extended by a general deformation condition.

A kinematical formulation can be derived from the principle of virtual displacements, which contains stresses $\sigma$ and displacements $u$. For a volume $V$ with a surface $S$ the following expression is used:

$$
\int_{V} A \delta u^{T} \sigma d V-\int_{V} \delta u^{T} f_{0} d V-\int_{S} \delta u_{S}^{T} A_{S}^{T} \sigma d S=0 .
$$

The operator matrix $A$ and transformation matrix $A_{S}$ are included. The internal strains $\varepsilon$ are connected with the external displacements $u$ by the kinematical relation

$$
\varepsilon=A u \text {. }
$$

With the restriction that only volumes without implied displacements $u_{s}$ will be investigated, the variational principle with internal strains changes to

$$
\int_{A} \delta \varepsilon^{T} \sigma d A-\int_{A} \delta u^{T} f_{0} d A=0 .
$$

If the influence of torsion and shear is to be neglected, only components of strain and stress in $x$ direction are considered.

$$
\int_{A} \delta \varepsilon_{x}^{T} \sigma_{x} d A-\int_{A} \delta u_{x}^{T} f_{0} d A=0 .
$$

By introducing the material law, plasticity conditions, the load vector $f_{0}$ and the deformation vector $u$

$$
\sigma_{x}=f\left(\varepsilon_{x, e l}\right), \sigma_{0}^{(-)} \leq \sigma_{x} \leq \sigma_{0}^{(+)},
$$

$f_{0}=\left[\begin{array}{lll}N_{x} & M_{y} & M_{z}\end{array}\right]^{T}, u_{x}=\left[\begin{array}{lll}\varepsilon_{x, m} & \kappa_{y} & \kappa_{z}\end{array}\right]^{T} \quad(5 \mathrm{a}-\mathrm{d})$ 
the variational equation becomes

$$
\begin{aligned}
\int_{A} \delta \varepsilon_{x, e l}^{T} f & \left(\varepsilon_{x, e l}\right) d A+\int_{A} \delta \lambda^{( \pm)} \sigma_{0}^{( \pm)} d A \\
& -\left[N_{x} \delta \varepsilon_{x, m}+M_{y} \delta \kappa_{y}+M_{z} \delta \kappa_{z}\right]_{S_{f}}=0 .
\end{aligned}
$$

Therefore, the following extremum principle can be derived:

Of all kinematically admissible deformation fields, that one will be adjusted, for which the total potential becomes a minimum.

The extremum principle can be formulated as:

$$
\begin{aligned}
\int_{A} F\left(\varepsilon_{x, e l}\right) & d A+\int_{A} \lambda^{ \pm} \sigma_{0}^{( \pm)} d A \\
-\left[N_{x} \varepsilon_{x, m}+M_{y} \kappa_{y}+M_{z} \kappa_{z}\right]_{S_{f}} \Rightarrow \operatorname{Min} &
\end{aligned}
$$

under the subsidiary conditions

$$
\begin{aligned}
\varepsilon_{e l, x}+\lambda^{(+)}-\lambda^{(-)} & =\varepsilon_{x, m}+z \kappa_{y}+y \kappa_{z} \\
\lambda^{ \pm} & \geq \mathbf{0} .
\end{aligned}
$$

Equation (7b) describes the deformation law and equation (7c) the non-negativity conditions. The extremum principle ( $7 \mathrm{a}-\mathrm{c})$ can be used to derive optimisation problems for the state analysis of cross-sections.

For the reinforcement design, a more general problem is needed. A set of subsidiary conditions can be derived by the method of Lagrange multipliers:

$$
\begin{aligned}
L & =\int_{A} F\left(\varepsilon_{x, e l}\right) d A+\int_{A} \lambda^{ \pm} \sigma_{0}^{( \pm)} d A \\
& -\left[N_{x} \varepsilon_{x, m}+M_{y} \kappa_{y}+M_{z} \kappa_{z}\right]_{S_{f}} \\
& +\int_{A} \lambda_{\sigma}\left(-\varepsilon_{e l, x}-\lambda^{(+)}+\lambda^{(-)}+\varepsilon_{x, m}+z \kappa_{y}+y \kappa_{z}\right) d A \\
& +\int_{A} \lambda^{( \pm)} \lambda_{R}^{( \pm)} d A,
\end{aligned}
$$

where $\lambda_{\sigma}$ is a function (depending on area A) which can be identified as the stress distribution and $\lambda_{R}^{( \pm)}$as a slack function for the residuum between the elastic stresses and the limit stresses

$$
\pm \lambda_{R}^{( \pm)}=\sigma_{x}-\sigma_{0}^{( \pm)} \quad \text { with } \quad \lambda_{R}^{( \pm)} \geq 0 .
$$

By variation of the Lagrange function $L(8)$ with respect to the unknowns, we get the Kuhn-Tucker conditions:

material law

$$
\sigma_{x}=f\left(\varepsilon_{x, e l}\right)
$$

plasticity conditions

$$
\sigma_{0}^{(-)} \leq \sigma_{x} \leq \sigma_{0}^{(+)}
$$

equilibrium conditions

$$
\begin{aligned}
N_{x} & =\int_{A} \sigma_{x} d A \\
M_{y} & =\int_{A} z \sigma_{x} d A \\
M_{z} & =\int_{A} y \sigma_{x} d A,
\end{aligned}
$$

deformation law

$$
\varepsilon_{e l, x}+\lambda^{(+)}-\lambda^{(-)}=\varepsilon_{x, m}+z \kappa_{y}+y \kappa_{z},
$$

complementary conditions

$$
\left(\sigma_{x}-\sigma_{0}^{( \pm)}\right) \lambda^{( \pm)}=0,
$$

non-negativity conditions

$$
\lambda^{( \pm)} \geq 0
$$

This system of equations and inequalities describes the section problem completely. By introducing a resistance multiplier $\mathrm{r}$ in the plasticity and complementary conditions, an optimum design problem can be formulated. In the case of minimum design, the objective function can be formulated as

$$
r \rightarrow \min \text {. }
$$

Only the plasticity (10b) and complementary (10e) conditions change to

$$
\begin{gathered}
\sigma_{x}-r \cdot \sigma_{0}^{( \pm)} \leq 0 \\
\left(\sigma_{x}-r \cdot \sigma_{0}^{( \pm)}\right) \lambda^{( \pm)}=0 .
\end{gathered}
$$

\section{Formulation of optimisation problems}

The extremum problem (10-13) is transformed by discretisation into an optimisation problem. Thereby the section integrations are transferred into summations by using fibre or layer models depending on the kind of loading. While for uniaxial loading layer models are sufficient, fibre models become necessary for biaxial loading. In case of sufficiently fine subdivision, the internal moments of inertia can be neglected and resulting axial forces are regarded.

The modelling is based on the following assumptions: for the section deformation the Bernoulli hypothesis is valid, between concrete and reinforcement a perfect bond is assumed.

By discretisation the equilibrium conditions (10c) are transferred into matrix notation

$$
\mathbf{A}_{\mathbf{G}} \mathbf{N}-\mathbf{f}_{\mathbf{0}}=\mathbf{0}
$$

where $\mathrm{A}_{\mathrm{G}}$ is the coefficient matrix of equilibrium and vector $\mathrm{N}$ contains the element forces. Vector $f_{0}$ contains the section loading $(5 \mathrm{c})$. The material behaviour of concrete (Fig 1a) under pressure is described by a $4^{\text {th }}$ order polynomial [6]

$$
\sigma_{c}=f_{c d} \sum_{k=1}^{4} a_{k} \varepsilon_{x}^{k}
$$


The form of the polynomial corresponds to the parabolarectangle diagram in [7]. The element force for a concrete fibre $\mathrm{i}$ is

$$
N_{c i}=F\left(\varepsilon_{x}\right)=A_{i} f_{c d} \sum_{k=1}^{4} a_{k} \varepsilon_{x}^{k} .
$$

The concrete tensile strength, therefore, is not activated.
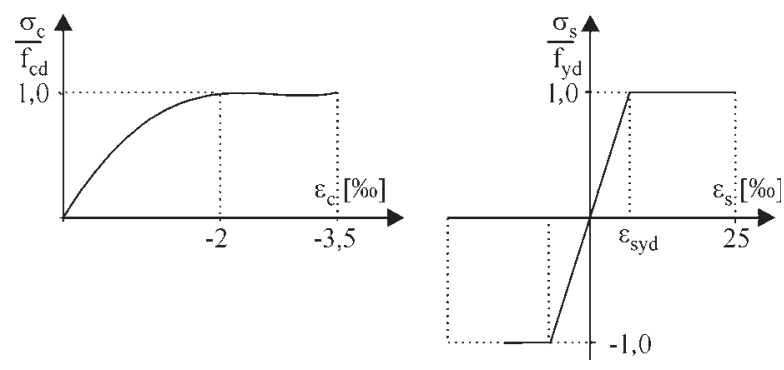

Fig 1. Material law of a) concrete, b) steel

The material behaviour of steel Fig 1b) in tension and compression is assumed to be bilinear. The linear part is calculated by

$$
N_{s i}=F\left(\varepsilon_{x}\right)=A_{s i} E_{s} \varepsilon_{x} .
$$

The element forces are limited by the plasticity conditions (12) written in matrix notation as

$$
\mathbf{A}_{\mathbf{P}} \mathbf{N}-r \cdot \mathbf{N}_{\mathbf{0}} \leq \mathbf{0}
$$

where $A_{P}$ is the coefficient matrix and vector $N_{0}$ contains admissible element forces. The deformation law (10d) that is formulated on the basis of the Bernoulli hypothesis is given in discrete form

$$
\mathbf{A}_{\mathbf{G}}^{\mathbf{T}} \mathbf{u}-\boldsymbol{\varepsilon}-\mathbf{A}_{\mathbf{P}}^{\mathbf{T}} \boldsymbol{\lambda}=\mathbf{0}
$$

where vector $\varepsilon$ contains elastic strains and vector $\lambda$ plastic strains. Plastic strains can appear if the plasticity conditions are fulfilled as equations. Therefore the complementary conditions (10e) get the form

$$
\lambda^{\mathbf{T}}\left(\mathbf{A}_{\mathbf{P}} \mathbf{N}-r \cdot \mathbf{N}_{\mathbf{0}}\right)=\mathbf{0} .
$$

According to the associative flow rule, the direction of plastic strains corresponds to the elastic ones. Therefore the plastic strains have to fulfil the non-negativity conditions

$$
\lambda \geq \mathbf{0} \text {. }
$$

\subsection{Deformation constraints}

For further discussion of deformation constraints without restriction of any kind, a rectangular doubly-reinforced concrete section is considered (Fig 2).

For section design at ultimate limit state, stress restrictions as well as deformation restrictions must be considered. The limit values of stresses and deformations are given by design codes, eg the German code for reinforced concrete DIN 1045-1. A definition for the limit values depending on loading is defined (Fig 3).

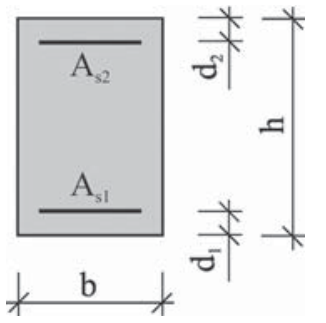

Fig 2. Doubly reinforced concrete section

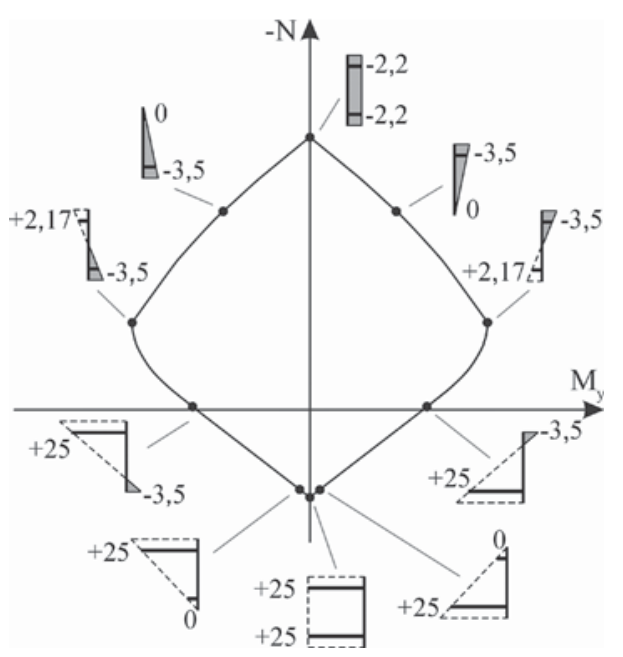

Fig 3. Limit states of deformation according to DIN 1045-1

The formulation of deformation restrictions in the optimisation problem can be accomplished by implementing a set of inequalities for each fibre. This procedure has the disadvantage that several load combinations have to be considered for the examination of multiple loading.

Alternatively, the deformation restrictions can be expressed by the plane parameters curvature $\kappa$ and axial strain $\varepsilon_{\mathrm{m}}$. By inserting the limit strains into the expressions, a convex space is created that contains each possible combination of plane parameters and/or section deformation (Fig 4).

The deformation restrictions can be integrated as inequalities into the optimisation problem. The equations for the borders of the deformation space are given in Fig 5. Every possible position of the compression zone can therefore be considered. The deformation conditions can be written in matrix notation

$$
\mathbf{A}_{\mathbf{D}} \mathbf{u}-\mathbf{u}_{\mathbf{0}} \leq \mathbf{0}
$$

where the matrix $A_{D}$ contains the unit vectors of each restriction and $\mathrm{u}_{0}$ the distance to the origin. The complete optimisation problem for section design is given in Table 1.

In this problem, the unknowns are the design parameter $r$, the vector of element forces $N$, and $\varepsilon$ corresponds to elastic strains, $\lambda$ is the vector of plastic strains and $\mathrm{u}$ the vector of the deformation plane parameters. 


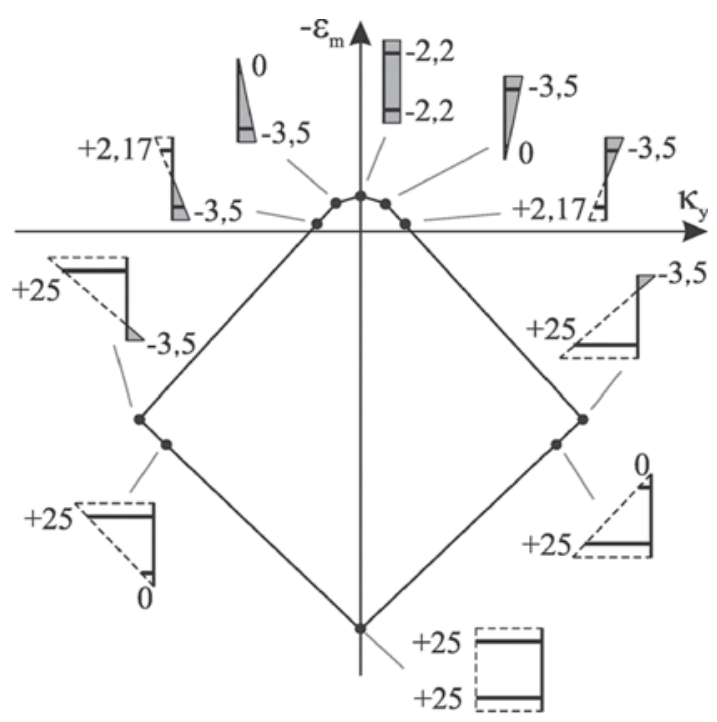

Fig 4. Interaction of plane parameters

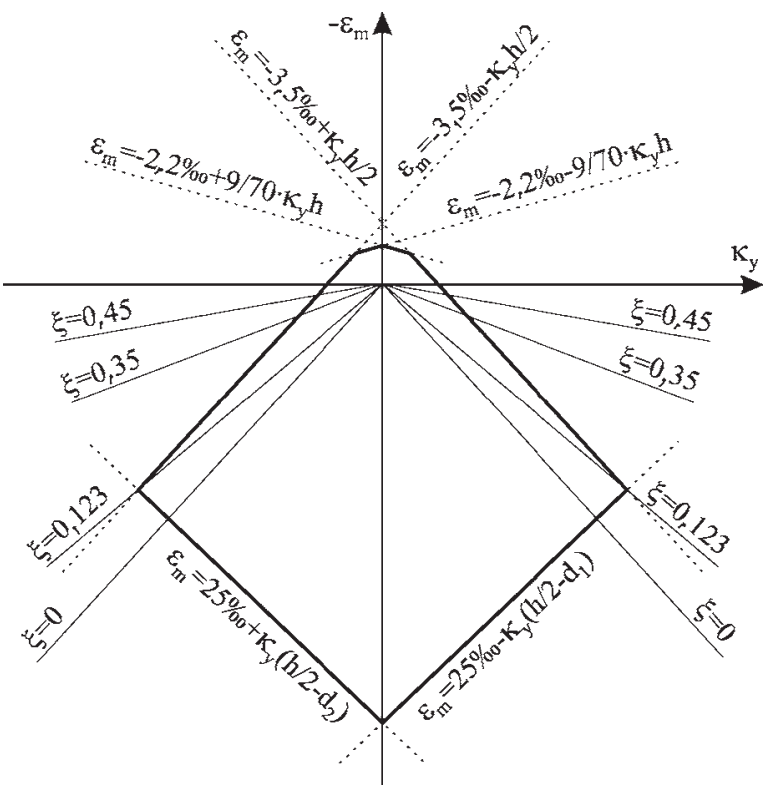

Fig 5. Ultimate deformation conditions for doublyreinforced rectangular cross-section

\section{Strategies for consideration of multiple loads}

In this chapter, two strategies for arranging the reinforcement in reinforced cross-sections are presented. Both strategies are possible with the optimisation problem presented in Table 1.

There are many approaches for considering multiple loads in the design process. Usually, the loading is split up into load cases, which are independent in occurrence and in sequence.

The common strategies for the design of reinforcement by considering multiple load cases can be divided into two groups:

1) Step-by-step analysis of the load cases

2) Simultaneous consideration of all load cases

Within strategy 1 , all load cases will be treated separately. This means that the design problem (Table 1) will be solved for every individual load case. The result is an optimal distribution of reinforcement within each load case. The consideration of all cases results in an envelope reinforcement (Fig 6).

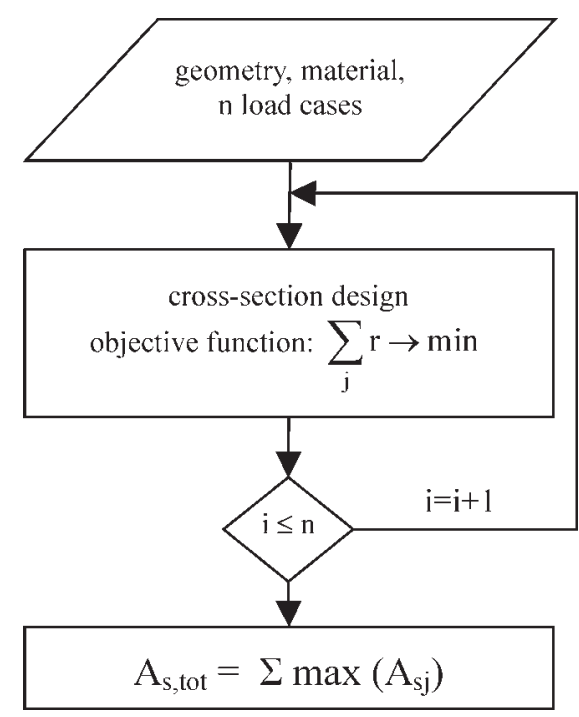

Fig 6. Design strategy 1 - step-by-step calculation

Table 1. Optimum design problem for determining the reinforcement

\begin{tabular}{|c|c|c|c|c|c|c|c|c|c|}
\cline { 2 - 9 } \multicolumn{2}{c|}{} & $\mathbf{N}$ & $\boldsymbol{\varepsilon}$ & $\boldsymbol{\lambda}$ & $\mathbf{u}$ & $\mathbf{r}$ & \multicolumn{2}{c|}{} \\
\hline $\mathrm{OF}$ & & & & & & $\mathbf{1}^{\mathrm{T}}$ & & $\rightarrow$ & $\mathrm{MIN}$ \\
\hline $\mathrm{EC}$ & & $\mathbf{A}_{\mathbf{G}}$ & & & & & $-\mathbf{f}$ & $=$ & $\mathbf{0}$ \\
\hline $\mathrm{PC}$ & & $\mathbf{A}_{\mathbf{P}}$ & & & & $-\mathbf{N}_{\mathbf{0}, \mathbf{S}}$ & $-\mathbf{N}_{\mathbf{0}}$ & $\leq$ & $\mathbf{0}$ \\
\hline $\mathrm{DL}$ & & $-\mathbf{1}$ & $\mathbf{F}(\boldsymbol{\varepsilon})$ & & & & & $=$ & $\mathbf{0}$ \\
\hline $\mathrm{CC}$ & $\lambda^{\mathrm{T}}($ & $\mathbf{A}_{\mathbf{P}}$ & & & & $-\mathbf{N}_{\mathbf{0 , S}}$ & $-\mathbf{N}_{\mathbf{0}}$ & )$=$ & $\mathbf{0}$ \\
\hline $\mathrm{DC}$ & & & & & $\mathbf{A}_{\mathbf{D}}$ & & $-\mathbf{u}_{\mathbf{0}}$ & $\leq$ & $\mathbf{0}$ \\
\hline $\mathrm{NNC}$ & & & & -1 & & & & $\leq$ & $\mathbf{0}$ \\
\hline
\end{tabular}


Therefore, the design parameter $r$ is introduced into the objective function (11) as a sum over all reinforcement elements $j$

$$
\sum_{j} r \rightarrow \min .
$$

A modification of strategy 1 is possible through the introduction of additional constraints. Therefore every reinforcement ratio can be given. The case of symmetrical reinforcement can be formulated with help of constraint

$$
A_{s 1}=A_{s 2} .
$$

It can also be useful in determining the interaction diagrams, which are used in design manuals.

With strategy 2, the loop over all load cases is replaced by a parallel calculation. Therefore, it is necessary to solve the $\mathrm{n}$ cross-section problems at the same time. The link between the problems is the design parameter $\mathrm{r}$, which specifies the amount of reinforcement. The vector $r$ will be part of the objective function as a sum over all reinforcement elements and over all parallel computed sections

$$
\sum_{n} \sum_{j} r \rightarrow \min .
$$

The complexity of the consideration of multiple loads is shifted by the parallel calculation into the design problem. The flow chart is simplified (Fig 7); however, the number of unknown quantities grows by factor $\mathrm{n}$ with the number of load cases. Therefore, it is reasonable to pre-select relevant load cases.

In Table 4, an example scheme for an optimum design problem considering 2 load cases is presented.

\section{Numerical example}

As a numerical example, a rectangular cross-section with the geometry shown in Fig 8 is investigated.

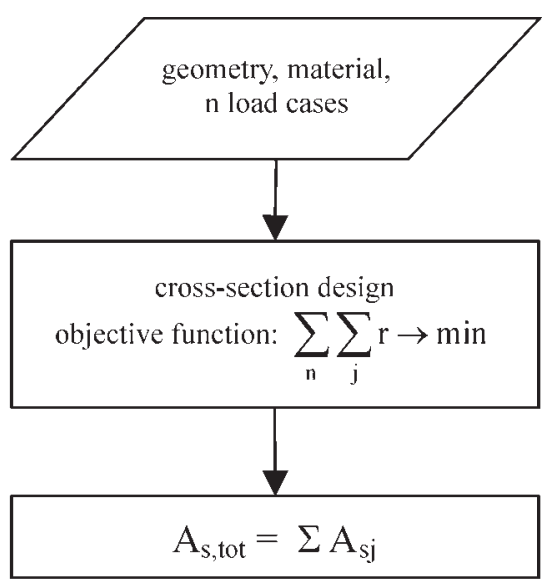

Fig 7. Design strategy 2 - parallel calculation

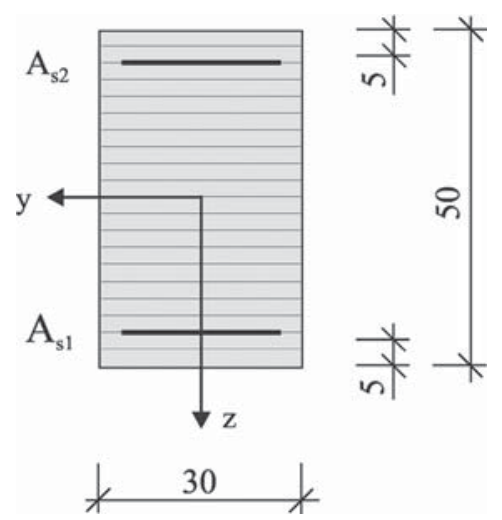

Fig 8. Sample cross-section

The following discretisation and material parameters are used:

\section{Concrete}

\section{C $30 / 37$}

$\mathrm{f}_{\mathrm{cd}}=-1,7 \mathrm{kN} / \mathrm{cm}^{2}$

$\mathrm{a}_{1}=-1,024323$

$a_{2}=-0,272046$

$\mathrm{a}_{3}=0,012152$

$\mathrm{a}_{4}=0,0085473$

\section{Steel}

BSt $500 \mathrm{~S}$

$\mathrm{f}_{\mathrm{yd}}=43,48 \mathrm{kN} / \mathrm{cm}^{2}$

$\mathrm{E}_{\mathrm{s}}=20000 \mathrm{kN} / \mathrm{cm}^{2}$

20 concrete layers

2 steel layers
The multiple loading, consisting of 5 load cases (LC), is given in Table 2.

Table 2. Load cases

\begin{tabular}{|c|c|c|c|c|c|c|}
\hline & & LC 1 & LC 2 & LC 3 & LC 4 & LC 5 \\
\hline $\mathrm{N}$ & {$[\mathrm{kN}]$} & 0 & -1000 & -300 & -600 & -2000 \\
\hline $\mathrm{M}$ & {$[\mathrm{kNm}]$} & 260 & 300 & 320 & -215 & -300 \\
\hline
\end{tabular}

For this load configuration, the section reinforcement will be designed. Likewise, the conventional procedure according to strategy 1 with symmetrical and asymmetrical reinforcement is evaluated.

In Table 3 the amount of reinforcement using either strategy 1 or 2 is given. The maximum reinforcement of every load case is chosen by using a step-by-step method (strategy 1). The total sum of the determined envelope reinforcement serves as comparison value.

The example shows that the step-by-step calculation with the symmetrical arrangement results in a $10 \%$ larger reinforcement than the asymmetrical arrangement.

A decrease of approx $28 \%$ can be obtained by using the optimum design (strategy 2). In this case, the reinforcement yields in both tension and compression zone.

The interaction diagram in Fig 9 shows that the optimal design method supplies the best adapted interaction curve for the given load cases.

It is clear that such a large reduction is only possible if, in the optimal case, an asymmetrical arrangement is present. 
Table 3. Reinforcement area for different design strategies

\begin{tabular}{|c|c|c|c|c|c|c|c|c|}
\hline & & LC 1 & LC 2 & LC 3 & LC 4 & LC 5 & $\mathrm{~A}_{\mathrm{s}, \text { tot }}$ & $\%$ \\
\hline \multirow{2}{*}{$\begin{array}{l}\text { Strategy } 1 \\
\text { symmetrical }\end{array}$} & $\mathrm{A}_{\mathrm{s} 1}\left[\mathrm{~cm}^{2}\right]$ & 14,61 & 8,67 & 14,76 & 5,82 & 13,89 & \multirow{2}{*}{29,52} & \multirow{2}{*}{100} \\
\hline & $\mathrm{A}_{\mathrm{s} 2}\left[\mathrm{~cm}^{2}\right]$ & 14,61 & 8,67 & 14,76 & 5,82 & 13,89 & & \\
\hline \multirow{2}{*}{$\begin{array}{c}\text { Strategy } 1 \\
\text { asymmetrical }\end{array}$} & $\mathrm{A}_{\mathrm{s} 1}\left[\mathrm{~cm}^{2}\right]$ & 15,68 & 10,10 & 19,11 & 0 & 16,68 & \multirow{2}{*}{27,02} & \multirow{2}{*}{92} \\
\hline & $\mathrm{A}_{\mathrm{s} 2}\left[\mathrm{~cm}^{2}\right]$ & 0 & 6,70 & 0 & 7,91 & 0 & & \\
\hline \multirow{2}{*}{$\begin{array}{c}\text { Strategy } 2 \\
\text { optimal }\end{array}$} & $\mathrm{A}_{\mathrm{s} 1}\left[\mathrm{~cm}^{2}\right]$ & \multicolumn{5}{|c|}{16,21} & \multirow{2}{*}{21,35} & \multirow{2}{*}{72} \\
\hline & $\mathrm{A}_{\mathrm{s} 2}\left[\mathrm{~cm}^{2}\right]$ & \multicolumn{5}{|c|}{5,14} & & \\
\hline
\end{tabular}

Table 4. Optimum design problem for 2 load cases

\begin{tabular}{|c|c|c|c|c|c|c|c|c|c|c|c|c|c|c|}
\hline & & $\mathrm{N}_{1}$ & $\mathrm{~N}_{2}$ & $\varepsilon_{1}$ & $\varepsilon_{2}$ & $\lambda_{1}$ & $\lambda_{2}$ & $\mathbf{u}_{1}$ & $\mathbf{u}_{2}$ & $\mathbf{r}_{1}$ & $r_{2}$ & & & \\
\hline OF & & & & & & & & & & $1^{T}$ & $1^{T}$ & & $\rightarrow$ & MIN \\
\hline EC & & $\mathbf{A}_{\mathbf{G}}$ & & & & & & & & & & $-\mathbf{f}_{0,1}$ & $=$ & 0 \\
\hline $\mathrm{EC}$ & & & $\mathbf{A}_{\mathbf{G}}$ & & & & & & & & & $-\mathbf{f}_{0,2}$ & $=$ & 0 \\
\hline ML & & -1 & & $\mathbf{F}(\varepsilon)$ & & & & & & & & & $=$ & $\mathbf{0}$ \\
\hline $\mathrm{ML}$ & & & -1 & & $F(\varepsilon)$ & & & & & & & & $=$ & $\mathbf{0}$ \\
\hline $\mathrm{PC}$ & & $\mathbf{A}_{\mathbf{P}}$ & & & & & & & & $-\mathbf{N}_{0, \mathrm{~S}}$ & & $-\mathbf{N}_{0}$ & $\leq$ & 0 \\
\hline $\mathrm{PC}$ & & & $\mathbf{A}_{\mathbf{P}}$ & & & & & & & & $-\mathbf{N}_{0, \mathrm{~S}}$ & $-\mathbf{N}_{0}$ & $\leq$ & 0 \\
\hline DL & & & & -1 & & $-\mathbf{A}_{\mathbf{P}}$ & & $\mathbf{A}_{G}{ }^{T}$ & & & & & $=$ & $\mathbf{0}$ \\
\hline DL & & & & & 1 & & $-\mathbf{A}_{\mathbf{P}}$ & & $\mathbf{A}_{\mathbf{G}^{T}}{ }^{\mathrm{T}}$ & & & & $=$ & 0 \\
\hline $\mathrm{CC}$ & $\lambda^{\mathrm{T}}($ & $\mathbf{A}_{\mathbf{P}}$ & & & & & & & & $-\mathbf{N}_{0, \mathrm{~S}}$ & & $-\mathbf{N}_{0}$ & )$=$ & 0 \\
\hline $\mathrm{CC}$ & $\lambda^{\mathrm{T}}($ & & $\mathbf{A}_{\mathbf{P}}$ & & & & & & & & $-N_{0, S}$ & $-\mathrm{N}_{0}$ & )$=$ & $\mathbf{0}$ \\
\hline DC & & & & & & & & $\mathbf{A}_{\mathbf{D}}$ & & & & $-\mathbf{u}_{0}$ & $\leq$ & 0 \\
\hline $\mathrm{DC}$ & & & & & & & & & $\mathbf{A}_{\mathrm{D}}$ & & & $-\mathbf{u}_{0}$ & $\leq$ & $\mathbf{0}$ \\
\hline $\mathrm{NNC}$ & & & & & & -1 & & & & & & & $\leq$ & 0 \\
\hline $\mathrm{NNC}$ & & & & & & & -1 & & & & & & $\leq$ & $\mathbf{0}$ \\
\hline
\end{tabular}

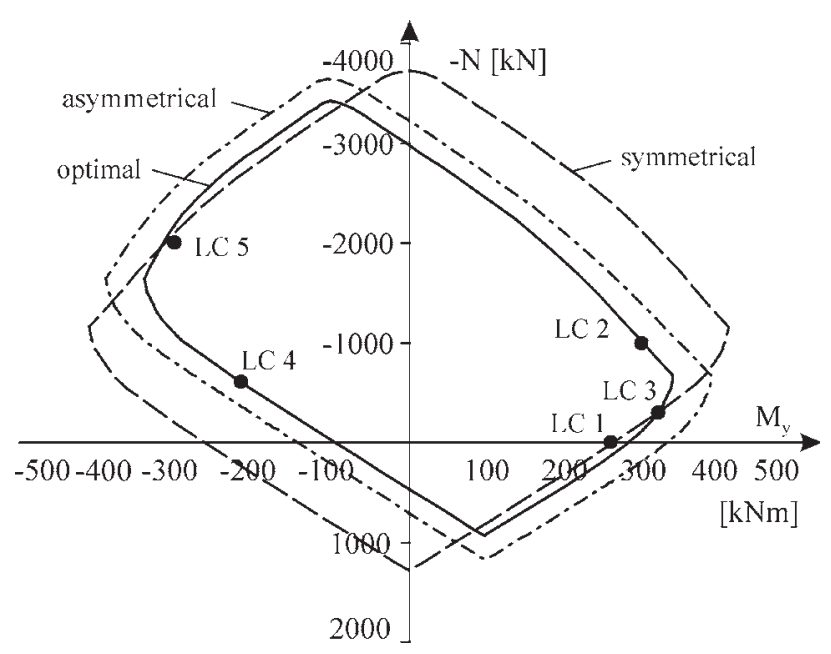

Fig 9. Interaction diagram due to different design strategies
If the load situation corresponds to a symmetrical arrangement, then a smaller reduction can be expected. In a special case, when the envelope load situation corresponds to a symmetrical interaction curve, no reduction of reinforcement can be expected. In this case, both strategies supply the same result.

\section{Abbreviations}

$\mathrm{OF} \quad$... objective function

EC $\quad$... equilibrium condition

ML ... material law

PC $\quad$... plasticity condition

DL $\quad$... deformation law

CC ... complementary condition

DC ... deformation condition

NNC ... non-negativity condition 


\section{Conclusions}

The strategies presented in previous chapters were used to determine the minimum reinforcement of crosssections due to multiple loads. By using generally formulated deformation conditions, the parallel calculation of all load cases is possible without the assumption of a failure deformation state.

The numerical example shows that a reduction of reinforcement is possible in comparison with common strategies. Best results can be expected by using asymmetrical reinforcement.

\section{Acknowledgement}

This research has been supported by the German Research Council (DFG) through Sonderforschungs-bereich 524 , which is gratefully acknowledged by the authors.

\section{References}

1. Prakash, A.; Argarwala, S. K. and Singh, K. K. Optimum Design of Reinforced Concrete Sections. Computers and Structures, Vol 30, Issue 4, 1988, p. 1009-1011.

2. Ferreira, C. C.; Barros M. H. F. M and Barros A. F. M. Optimal Design of Reinforced Concrete T-sections in Bend- ing. Engineering Structures, Vol 25, Issue 7, June 2003, p. $951-964$.

3. Rafiq, M. Y. and Southcombe, C. Genetic Algorithms in Optimal Design and Detailing of Reinforced Concrete Biaxial Columns Supported by a Declarative Approach for Capacity Checking. Computers and Structures, Vol 69, Issue 4, Nov 1998, p. 443-457.

4. Marx, S., Application of Mathematical Programming for Geometrical and Physical Non-linear Calculation of Reinforced Concrete Structures (Anwendung der mathematischen Optimierung bei der geometrisch und physikalisch nichtlinearen Analyse von Stahlbetontragwerken), $\mathrm{PhD}$ thesis, Bauhaus-University Weimar, Germany, 2000 (in German).

5. Hahn, S. Cross-section Analysis by Methods of Mathematical Programming. In: Proc of 4th International PhD. Symposium in Civil Engineering, Munich, 2002.

6. Jahn, Th. The Approximation of the Non-linear StressStrain Behaviour of Concrete by Polynomials. Concrete and Reinforced Concrete Construction (Beton- und Stahlbetonbau), Vol 92, Issue 6, 1997, p. 156-160 (in German).

7. DIN 1045-1: Concrete, Reinforced and Prestressed Concrete Structures (Tragwerke aus Beton, Stahlbeton und Spannbeton). German Institute for Standardisation, 2001 (in German).

\section{OPTIMALUS GELŽBETONINIŲ ELEMENTŲ ARMATŪROS PROJEKTAVIMAS İVERTINANT DEFORMACIJŲ SUVARŽYMĄ}

\section{E. Raue, S. Hahn}

\section{Santrauka}

Pateiktas gelžbetoninių elementų optimalus armatūros projektavimo algoritmas ịvertinant bendrą kelių apkrovimo variantų poveiki. Ši problema išspręsta taikant netiesinio matematinio programavimo metodus. Pirmojoje dalyje taikant ekstremumo principus parenkamas skaičiavimo modelis. Antrojoje dalyje lyginami du skaičiavimo algoritmai: laipsniškas (angl. stepby-step) ir paralelinis. Pabaigoje pateikiamas skaitinis pavyzdys. Analizė rodo pasiūlytojo algoritmo efektyvumą, palyginti su tradiciniais projektavimo metodais. Taikant pasiūlytą metodiką reikia mažiau armatūros nei taikant tradicinius metodus.

Raktažodžiai: optimalus projektavimas, skerspjūvis, gelžbetonis, daugialypis apkrovimas, matematinis programavimas.

Professor Dr-Ing Habil Erich RAUE has been working since 1976 at the Bauhaus-University Weimar, Germany. Leader of the Dept of Reinforced Concrete Structures. He has participated in different standard committees and is actually a member of the Committee for Aerated Concrete of the German Institute for Construction Engineering (DIBt) and of the Collaborative Research Centre 524 of the German Research Foundation (DFG). He teaches reinforced and prestressed concrete design, non-linear analysis of $r$ c structures and structural design. He conducted research in different domains: non-linear and time-depending behaviour of $\mathrm{r} / \mathrm{c}$ structures under low-cyclic and impact loading, structural analysis based on non-linear optimisation methods, composite structures and alternative reinforcement, structural safety and reliability, shell structures. He has published about 170 papers and is co-author of 3 monographies.

Dipl-Ing Stephan HAHN is a PhD student at the Dept of Reinforced Concrete Structures at the Bauhaus-University (Weimar). He did his diploma in Civil Engineering in 2001. Actually he participates in the Collaborative Research Centre 524 of the German Research Foundation (DFG). He has published the results of his research on the behaviour of $\mathrm{r} / \mathrm{c}$ elements under cyclic loading, the shakedown behaviour of $\mathrm{r} / \mathrm{c}$ structures and the application of optimisation strategies in 7 papers. 